\title{
10 Social generations in popular culture
}

\author{
Ida Tolgensbakk
}

\section{Introduction}

Community making - creating groups of people who have something in common - also means creating boundaries towards the other (Barth 1969). Social generations today seem to be popular in the public imagination as a means of creating such boundaries. This chapter discusses how the concept of social generation - an approach originally stemming from the work of Karl Mannheim - seems to have transitioned from academic interests to popular culture. Importantly, it has also moved back into academia, with popular terms being used in scholarly works. This is not necessarily negative but definitely bears the risk of superficial and trivial analyses.

In the following, I will start by presenting Mannheim's concept of generation and the main ways it has been applied in research in the post-war decades. The different applications, not surprisingly, reveal that comparison across contexts on the basis of generational terms is bound to be difficult. My main point in this text, however, is to discuss whether we can see the contours of the idea of a social generation becoming an emic term, that is, a term used by people to self-identify as belonging to one group or the other. Does it have a place in how people view themselves in the world? I will discuss these questions by examining how social generation is used in contemporary popular culture.

\section{Still a problem of generations}

German sociologist Karl Mannheim posited in his 1928 essay on what he called the problem of generations that important societal events would give youth of the same age groups similar impressions, giving them something in common (Mannheim 1952 (1928)). With his approach, he suggested that we could similarly view social generations as we do socioeconomic class, or gender. The "problem" he was discussing was that of the progress of history: different birth cohorts being influenced in different ways by the same historical experiences, becoming the polyphony of thinking within the same era (Mannheim 1952 (1928):283) that together create a harmony, a zeitgeist. Mannheim's concept of generation combines the biological rhythms of birth and ageing with historical events beyond 
the individual. In doing so, he attempted to reach an understanding of how society changes - how individuals change and how individuals change society. In other words, it is a concept that merges two approaches to time: the external and the internal. The term "generation" was originally a term reserved for kinship relations: between parents and offspring, and the time passing between the two. Mannheim's use is close to the meaning of (age or birth) cohort, that is, all individuals born around the same time. To avoid confusion, Jane Pilcher suggested using the term "social generation" when referring to a Mannheimian understanding of the term (Pilcher 1994:483).

Mannheim's concept has become incredibly influential and has been referred to, applied, tested, and criticised within his own field - the sociology of knowledge - and beyond for almost a century. With what seems to be renewed interest in the concept post-2000, there is reason to take a closer look at what it has been used for. Later researchers have tried applying his notion of generation to studies of the life course, historical processes, societal conflict, and more. Different age groups will experience different historical events - such as war or technological change - from different angles. Demographically, birth cohorts rhythmically differ in size. Building on Bourdieu, June Edmunds and Bryan S. Turner theorised that these rhythms will result in relatively passive generations being followed by relatively more collectively acting generations (Edmunds and Turner 2002, Edmunds and Turner 2005). Some scholars portray these processes as universal or global. Others focus on local reactions to dramatic events and developments. Importantly, the concept of social generations has moved outside of academia and scholarship and has become an everyday concept used by people to describe themselves and to discuss societal change. It has also proved extremely useful for trend research and labour market consultancies trying to understand and predict hence profiting on - new generations of youth. With or without explicit reference to Mannheim's concept, people will speak of "generation gaps", reminisce nostalgically about "our generation" or put their hopes to the "new generation". The term has, in short, become a way for people to make sense of their worlds, whether as scholars or otherwise.

\section{Developments in the concept of social generations}

It seems almost natural that a German writer would become interested in the issue of social change between generations after the First World War. "The Lost Generation" was the name given by Gertrude Stein to denote a group of American writers in Paris after the war, but the term has since been used to describe all those who were young during that war (and, metaphorically, all kinds of youth cohorts in socioeconomic trouble). Part of the birth cohorts that came of age during the war was literally lost - dead on the battlefields - whilst the surviving rest felt spiritually lost. Equally natural it may seem that Mannheim's text was translated to English in 1952, when another war generation was coming to terms with living in their own post-war world. However, other ways of seeing social change, and youth, were more dominant at the time: structural functionalism 
and the work on youth subculture coming out of Birmingham. Scholars did use Mannheim's social generation in some research fields, but the perspective was not the dominant one. As Woodman writes, only until the years after 2000 have social generations and the writings of Mannheim had a real revival (Woodman 2016).

The main critique of Mannheim's concept of social generations as an analytical tool is that it is too vague to apply to empirical work and that it does not sufficiently consider the obvious, large intra-generational differences. However, Mannheim stressed that for individuals born within the same year span to become a generation, they must share social location. He also discussed the fact that within the same group, people may have more than one way of reacting to the same experiences - creating potential polar responses (Woodman 2016:21).

In recent decades, several efforts have been made to apply social generations to empirical data or to develop the concept into overarching theories. I have already mentioned Edmunds and Turners' work on the rhythm of active generations following passive ones. Others have, for instance, used generational concepts to overcome what they perceived as a reductionist focus on youth as a transition into adulthood (Cohen and Ainley 2000). In a critique of what they called "a new emerging orthodoxy in youth studies", France and Roberts placed the resurgence of generation as an analytical approach to the work at the Melbourne Youth Research Centre (France and Roberts 2015) and their longitudinal Life Patterns research programme. The work of the Melbourne researchers insisted on generation as an analytical framework with explanatory possibilities (Wyn and Woodman 2006). But long before the revival of social generation as an object of academic study post-2000, the concept took on its own life in popular writings. The most influential of these was the writings of Strauss and Howe, starting with the book Generations: the History of America's Future, 1584 to 2069 (Strauss and Howe 1991). What has become known as the Strauss-Howe generational theory posits that history is characterised by recurring personas, four in number, changing every 20-25 years. After a completed cycle of four generations, a crisis appears. The theory is definitely not supported by empirical evidence, but this has not lessened its popularity in, for instance, management literature, marketing - and the popular imagination. Edmunds and Turner's work can be seen as one variety of this way of thinking about sociocultural generational change, although they present it in a much more serious and empirically founded manner.

I will argue that parts of the underlying ideas of Strauss and Howe - the inevitable changes that spur (or follow) generational conflict, the recurring waves of active, reactive, reactionary, and revolutionary youth groups - have struck the popular mind. They present a simple, often dramatic, way of discussing historical and social change. They offer an attractive narrative of us versus them, and (often) a call for immediate action. In his 2013 article, Jonathan White named the phenomenon "generationalism", defined as "the systematic appeal to the concept of generation in narrating the social and political" (White 2013:216). White discussed British popular writings on generation and identified five themes or ways in which generation is used in these writings: as a historical explanation, as 
periodisation, as sources of community, as a moral language to identify injustice, and in discussions of social division.

Generationalism has also seeped into scholarly works. This creates conceptual cloudiness, not only when generational terms originating in an Anglo-American context is used on data from outside of the United States and the United Kingdom, or in comparative studies, but also when named social generations are taken for granted as social objects.

\section{Globalising local (Anglo-American) terms}

The generation terms that have become the most prevalent to denote youth groups in the 20th century are the Silent Generation, the Baby Boomers, Generation X, and Millennials. They are used across the Anglo-American area and are adapted in different versions in related languages and cultures. Sometimes, these terms are easily translatable and relevant to languages and cultures outside the Anglo-American area: for instance, many European countries experienced a baby boom after the Second World War, and in many countries, this was a generation that grew up to unprecedented access to education and wealth. However, the terms do not, of course, fit everywhere, and even when they fit, they may denote slightly different things.

One version of operationalising Mannheim's theory of social generations is applying current generational terms to discuss local demographical developments. One example is when Karisto, in the article "Finnish Baby Boomers and the Emergence of the Third Age", used the Anglo-American term as a starting point. He discussed how Finland emerged from the war against the Soviet Union, then the Lapland War, with an extraordinary increase in birth rates, which differs from other European countries in that it was both very large and very short (Karisto 2007). Karisto mentioned in passing that a certain subsection of Finnish Baby Boomers identify as "the 60s generation", referring to the political turmoil of their youth, but that most would refer to themselves merely as the "big age group", which is the Finnish term most equivalent to Baby Boomers. He then went on to his main point - the life course of Finnish Baby Boomers, how they changed and were changed by society through urbanisation, modernisation, and structural changes, and how they are now re-shaping older age.

Another way of using American terms for post-war social generations is explicitly re-developing them. For the Netherlands, inspired by Mannheim, Becker suggested five generations (see Figure 10.1) and argued that these may be relevant for other European societies (Becker 1997, 2000). He called the equivalent of the American Baby Boomers the "protest generation", which fits well with the way these birth cohorts are spoken of in other Western European countries. Again, some of the Anglo-American delineations and terms fit rather well, whereas others do not.

In Norway, the big birth cohorts of the first post-war years resemble those of the United Kingdom and the United States. However, the social generation of these birth cohorts has had a competing name to the English term Baby Boomers. Sekstiattere - the generation of 1968 - became the general term for all those taking part in the European-wide 
student-led protests of the late 1960s. Since this term has been so common, Norwegian Baby Boomers have, perhaps more often than in Anglo-American contexts, been seen as revolutionaries (and, lately, as revolutionaries failing their cause as they now retire from public life). The following generation, Generation Xers, has often been nicknamed Ironigenerasjonen (the Ironic Generation) in Norwegian, because of the popularity of irony and sarcasm as comedic genres of the time (effectively erasing, for instance, the environmental activism of the same age cohorts). Aakvaag is one of the Norwegian scholars most active in naming the Norwegian 21st-century generations, at one point proposing the term Generasjon Lydig (Generation Obedient), for the 1980-1990 birth cohorts (Aakvaag 2013). This was rather heavily debated in Norwegian media, but that term, and the similar term Generasjon Prestasjon (Generation Achievements), for the cohorts born around 2000 (Madsen 2018) seems to stick, at least for now. Beyond these terms, it is common in Norwegian-language social media to use Anglo-American terms to debate local and specific phenomena. This does not mean that Norwegian terms are not also used. For instance, the terms Millennials or Generation Y may be used when discussing pop cultural issues, while Utøyagenerasjonen (the Utøya generation, referring to the site of the terror attacks of 2011) may be used about the same birth cohorts when discussing political engagement amongst young adults.

Spain has a distinctive cultural and economic trajectory through the 21 st century compared with the United States, the United Kingdom and most of Northern Europe. To a certain degree, Spain stayed out of the two world wars, but was instead impacted by a civil war from 1936 to 1939, which ended with the Franco dictatorship (1939-1975), isolating the country and holding back economic development for decades (Díez-Nicolás 2008). Díez-Nicolas, studying values, therefore proposed very different timings of the social generational changes in Spain. For instance, he named those with birth years of 1937-1951 the "Economic Development Generation" (Díez-Nicolás 2008:251). Contrary to Díez-Nicolas, Caballero and Baigorri found the Anglo-American terms useful, although with adjustments (Caballero and Baigorri 2019). They argued explicitly in reference to Strauss and Howe and chose terms that are very similar to the Anglo-American ones. To classify Spanish generations, they proposed the terms "Silenced" (born 1914-1928), "Francoist” (1929-1943), "Baby Boom” (1944-1958), “Generation X” (1959-1973), “Generation Y" (1974-1988), and “Generation Z” (1989-2003).

For the latest generational youth groups, Spanish media has proposed a variety of names, such as Generación táctil, referring to the youngest children of today, growing up with smartphones and digital schools. Generación perdida (Lost Generation) is perhaps the most commonly used term for what many other countries know as Millennials. In Spain, which was particularly hit hard by the financial crisis, these birth cohorts finished their education only to enter a labour market that had nothing to offer them. Some of these young adults now find their jobs in danger for the second time in a country particularly vulnerable to decline in tourism following COVID-19, something that has not been lost on Spanish commenters (Pérez-Lanzac 2020). Interestingly, at one point, a group of their grandparents (in family generational terms) chose the generational term iaioflautas (a play on the derogatory perroflautas, which is used to describe the young 
Table 10.1 Social generational terms

\begin{tabular}{|c|c|c|c|}
\hline $\begin{array}{l}\text { The United States } \\
\text { according to Strauss } \\
\text { and Howe }\end{array}$ & $\begin{array}{l}\text { The Netherlands } \\
\text { according to Becker }\end{array}$ & $\begin{array}{l}\text { Spain according } \\
\text { to Caballero and } \\
\text { Baigorri }\end{array}$ & $\begin{array}{l}\text { Norway according } \\
\text { to Aakvaag }\end{array}$ \\
\hline $\begin{array}{l}\text { 1901-1924 } \\
\text { G.I. }\end{array}$ & $\begin{array}{l}\text { 1910-1930 } \\
\text { Pre-war }\end{array}$ & $\begin{array}{l}\text { 1914-1928 } \\
\text { Silent }\end{array}$ & \\
\hline $\begin{array}{l}\text { 1925-1942 } \\
\text { Silent }\end{array}$ & $\begin{array}{l}\text { 1930-1940 } \\
\text { Silent }\end{array}$ & $\begin{array}{l}\text { 1929-1943 } \\
\text { Francoist }\end{array}$ & $\begin{array}{l}\text { 1920-1930s } \\
\text { Gerhardsen } \\
\quad \text { Generation }\end{array}$ \\
\hline $\begin{array}{l}\text { 1943-1960 } \\
\text { Baby Boom }\end{array}$ & $\begin{array}{l}1940-1955 \\
\text { Protest }\end{array}$ & $\begin{array}{l}\text { 1944-1958 } \\
\text { Baby Boom }\end{array}$ & $\begin{array}{l}\text { 1940-1950s } \\
\text { The Generation of } \\
1968\end{array}$ \\
\hline \multirow[t]{3}{*}{ Generation X } & $\begin{array}{l}\text { 1955-1970 } \\
\text { Lost }\end{array}$ & $\begin{array}{l}1959-1973 \\
\text { Generation X }\end{array}$ & $\begin{array}{l}\text { 1960-1970s } \\
\text { The Irony } \\
\text { Generation }\end{array}$ \\
\hline & $\begin{array}{l}1970- \\
\text { Pragmatic }\end{array}$ & $\begin{array}{l}\text { 1974-1988 } \\
\text { Generation Y }\end{array}$ & $\begin{array}{l}\text { 1980-1990s } \\
\text { Generation } \\
\text { Obedient }\end{array}$ \\
\hline & & $\begin{array}{l}\text { 1989-2003 } \\
\text { Generation Z }\end{array}$ & \\
\hline
\end{tabular}

Source: Adapted by the author from Caballero \& Baigorri, 2019.

protesters against austerity measures following the financial crisis) to denote their dedication to once again protect the young.

A summary of some of the many re-developed social generational terms can be seen in Table 10.1.

\section{"Generation" as an emic term}

To a certain degree, the generalisation inherent in this method of naming generations can be useful for comparative purposes - explaining why value markers connected with different birth cohorts vary between those in Southern European and those in Northern European countries, or discussing the impact of large postwar birth cohorts in different countries. However, the act of naming is in itself powerful and should be used with caution. In the case of discussing sociocultural changes, it is perhaps more counterproductive than useful as an analytical tool. The risk of misunderstandings across cultural and linguistic borders is obvious: the Baby Boomers in Finland are not the same as Baby Boomers in the United States, and the Lost Generation in the Netherlands is not the same as the Ironic Generation in Norway. The Silent Generation refers to different age cohorts in Spain compared with what it refers to in the United States. Even when the comparative aspect is left aside, the risk of context-poor analysis and unhelpful generalisation is high. Although useful in some ways when discussing social change 
as a phenomenon, it has proven difficult to operationalise as an analytical term (Aboim and Vasconcelos 2014, Eyerman and Turner 1998). However, as social generation as a concept has taken on a life of its own, it does make sense to take it seriously. It does make sense to, for instance, use the term as an entry point into an analysis of whether the beliefs the public has (or the politicians claim about) certain social generations match reality, as Slagsvold and Hansen did in this volume. I would also like to argue that there is value in studying what social generation is used for locally, emically, in popular or folk culture and media debates. Why has it caught on to such a degree that people use generational terms as identity markers, as pejoratives and as arguments? Speaking of generations as shorthand for complex societal phenomena is a popular way of creating clickbaits in online newspapers or stirring debate on social media and beyond around the world.

If we take Mannheim's theory of social generations seriously, we would need to consider that groups of people will have to name themselves for a social generation to be considered a social (and political) entity. This is an empirical question to be investigated in each specific case. Do groups of people belonging to roughly the same birth cohorts across places, perhaps even across national borders, gender, and class, consider themselves a group? Do they feel and express that they have something in common? In the last remaining pages of this chapter, I will show some examples of how social generational terms are used in contemporary culture.

\section{Generation in popular culture}

It does seem as if social generation as a way of expressing sociocultural belonging has become more common in popular culture (White 2013:216). Dating is difficult, but the real surge seems to be after approximately the year 2000, following (or being followed by) renewed scholarly interest. Strauss and Howe's many books on the topic have been bestsellers in the United States, and the many writers following in their footsteps have sold all over the world, whether as more scholarly work or within the self-help genre. Making analyses of the zeitgeist through naming, shaming, and/or trying to understand the current generation is big business. Psychologist Twenge published her book Generation Me in 2006, arguing that young adults of this generation are "tolerant, confident, open-minded, and ambitious, but also disengaged narcissistic, distrustful, and anxious" (Twenge 2006). It only took entrepreneurs Greenberg and Weber two years to publish their book Generation $W e$, with the more positive view that this generation would progressively change the whole world for the better (Greenberg and Weber 2008). The Swedish consulting firm Kairos Futures was perhaps more strategic when it named its publication The MeWe Generation, stressing the nuances in a generation supposedly consisting of people who are "born individualist, but no hard-core egoists" (Lindgren, Fürth, and Lüthi 2005). None of these takes on the young generation seems to fit completely with any of White's five themes in British generationalism mentioned above. They are oriented towards categorising the coming generation and hence telling the future, rather than, e.g., warning of social division. 
Beyond the scholarly and popular world of books on generation, other media also participate in the emerging discourse on social generations. Online media lures clicks from never-ending headlines such as "30 Things Only Those Who Are True '90s Kids Would Understand" (Prince, Undated) or "10 Indisputable Signs You're A Boomer" (Shah, 2014). These are the kinds of feel-good articles mostly created to start nostalgic discussions among readers (i.e. "Oh, do you remember?"), or debates about not being one of those kinds of '90s kids. They create a feeling of belonging, of being part of a group. They create a discourse similar to that of the social media phenomenon of user-created Facebook communities named "You Know You Grew Up in India in the 90s When". ${ }^{1}$

\section{Generation on social media}

I have conducted a simple social media analysis to obtain an overview of what generation as a concept looks like in the everyday popular imagination. Ten years ago, forums would have been the best way to find user-created communities spanning different age groups, and soon there will probably be other fields more relevant than Facebook. But at the moment, Facebook is perhaps the only place where all age groups (except the youngest) are at least somewhat present. I have concentrated on the terms related to Boomers and Generation X - again a convenience sample, as both groups are relatively present on Facebook.

These are often humour sites, but they are just as often sites for sharing pictures from that time (or a place at that time). Sometimes they start out as humour sites but develop into being groups for socialising - in the case of groups dedicated to a place, they are often popular amongst emigrants (Tolgensbakk 2017a). Being a member of such groups is, of course, mostly a pleasant online pastime, but it is also a statement. Both placing yourself in a decade and placing yourself as originating from a particular city means identifying with and making visible to others an aspect of who you consider yourself to be. Interestingly, most of these types of groups on internet forums and on Facebook are not naming themselves after social generations such as "Generation $X$ " or the like. When referring to time, rather than place, as the identifier, people prefer to use decades rather than generations, both in English-language and Norwegian social media. Searching Facebook is not easy, and making a full comparison is not possible within the boundaries of this article. However, in January 2021, searching Facebook for open communities with "Generation X" or "Baby Boomer" in the name yielded mostly Facebook sites, whereas searching for communities with "70's kids" or "50's kids" in the name yielded mostly Facebook groups. Sites are usually created by administrators with something to sell or communicate and they have "followers". Groups are created with a community-building intention and have "members". Amongst the Norwegian-language communities, almost none is named using generations, but several use decades as a denominator, such as "Vi som husker 80og90tallet" (We who remember the 80 s and 90 s). ${ }^{2}$

Most of the generation-named communities on Facebook seem to be humour sites (e.g. "Edgy Gen-X Memes for Middle Aged Screams"3), but at least some of the decade-named communities seem to be intended less for humorous purposes 
and more, or at least also, for socialising and bonding (such as "Grew Up in the $70 \mathrm{~s}$ and $80 \mathrm{~s} " 4)$. Beyond that, they are rather similar in what activities they encourage - such as sharing high school pictures, reminiscing pop music hits, and, above all, sharing memes about how it was to be young in the chosen period.

\section{Bonding, and bonding through boundaries}

Some of the popular cultural approaches to defining social generational membership are not about bonding, but rather about the opposite - defining others or marking distance. These may be relatively benign, seemingly just explaining generational differences. Sites such as Buzzfeed have been publishing articles or, more precisely, Twitter-post collections, such as "31 Things Boomers Love That Most Millennials Just Don't”' (Stopera, 2019) for several years. These are all ridiculing a chosen social generation, and create bonding through stating what we are not, rather than what we are. An important way of creating groups is after all to create boundaries towards the "other" (Barth 1969), and if we are to look functionally at what use the idea social generations are to the popular imagination, boundary-making is probably one of its most important traits.

An often-overlooked aspect of Mannheim's original discussion of the importance of social generations is his emphasis on how social generations are collectives created from shared experience (Purhonen 2016:97). Under certain circumstances, shared experience result in self-consciousness as a group; for Mannheim, the potential for a shared political worldview and project is of importance. Media will embrace pop psychology to diagnose Baby Boomers as being digitally ignorant or Millennials as destroying the economy. In the meantime, it may just happen that someone finds the stickers meaningful enough to spur the formation of communities, or incite actions.

After years of Boomer-Millennial debates, the genre of debating generations became a meme in itself. It was recognisable enough to be shared outside of AngloAmerican social media (Tolgensbakk 2017b). In June 2020, whilst the serious media discussed whether Black Lives Matter-demonstrations and climate strikes around the world were the birth of Generation Z as a political entity, Twitter user@KWAIG quipped that she had spotted a paradigm shift - Millennials becoming the Old.

Whilst the past years have seen Millennials being blamed for everything that is wrong with young people as a group (narcissism, naiveite or otherwise), and the Baby Boomers being blamed for everything that is wrong with Old People as a group (or simply being brushed off with an "OK boomer"), suddenly, there was someone blaming a new generation for being the entitled young: Generation $\mathrm{Z}$. Underneath@KWAIG's simple statement of “oh no it's happened. The paradigm shift", she shared three screengrabs of other tweets:

GenZ doesn't know what it's like to play outside ... to roam the neighbourhood untracked via smart phone. Us Milennials were the last to have a REAL childhood. We were free and proud of our streets. Like in the movies. Goonies never die! 
GenZ has been subjected to the most mindless apps, app celebrities.

Older millennials like myself had the privilege of growing up where we didn't reach for our phone every minute.

All the tweets visible in the screengrabs (quoted above) are statements of belonging. The tweeters are all positing themselves as Millennials with better childhoods, upbringing or just common sense compared to the coming generation. Even the statement above the three tweets she captured can, strictly speaking, be seen as a way of placing oneself in a community - that of the one who realises that Millennials are growing old. @KWAIG is from Glasgow, and the tweets she commented on are from New Yorkers. But the audience interacting on her reaction was from all over the world. At the time of this writing, the tweet has reached 26000 likes and received more than 6000 retweets. Important for the discussion in this chapter is that the tweet has been found meaningful enough to be retweeted by Scandinavian, Spanish, and Dutch tweeters.

\section{Conclusion}

Media discourses on social generations may be entertaining, but from a scholarly point of view, researchers should be cautious when using popularly named social generations in their analysis. With the possible exception of Baby Boomers - as so many countries involved in the Second World War had a literal boom of babies in the late 1940s - generalising across local contexts will lead to more possibilities for misunderstanding than anything else.

I believe that there is reason to be very careful when using social generations in analysis, and perhaps even more when conveying results from demographic studies to the public, to avoid confusion and generalisation. On the other hand, it may be that the public finds social generation terms to be meaningful stickers, something that defines them as individuals or makes them feel that they belong to a larger community. If that is empirically the case, if these concepts are emic to those groups and communities we study, it makes absolute sense from an ethnographic point of view to delve into the opportunity for exploring imagined communities beyond the classic categories.

The uses and abuses of Mannheim's ideas about social generations - long after his essay ceased to be the sole association to the term - are a reminder of the creative life academic terms take on outside of academia. We need to be wise about how to use popular enthusiasm around that in a productive way. At the same time, it is possible to be enthusiastic about, and look closely at how people use social generations to negotiate their own place in the world.

\section{Notes}

1 Facebook site started in 2010, 160000 followers per December 2020. 
2 Created in 2014, with 1900 members, which is rather big for a non-commercial Norwegian group.

3 Created in 2017, with 12000 followers as of January 2021.

4 Created in 2017, with 304000 members as of January 2021.

\section{Literature}

Aakvaag, Gunnar Colbjørnsen. 2013. Generasjon Lydig. Aftenposten.

Aboim, Sofia, and Pedro Vasconcelos. 2014. "From political to social generations: A critical reappraisal of Mannheim's classical approach." European Journal of Social Theory 17(2): 165-183. doi: 10.1177/1368431013509681.

Barth, Fredrik. 1969. "Introduction." In Ethnic Groups and Boundaries: The Social Organization of Culture Difference, edited by Fredrik Barth. Oslo: Universitetsforlaget.

Becker, H. 1997. De Toekomst van de Verloren Generatie. Amsterdam: Meulenhoff.

Becker, H. 2000. "Discontinuous change and generational contracts." In The Myth of Generational Conflict: The Family and State in Ageing Societies, edited by S. Arber and Attias-Donfut. London: Routledge.

Caballero, Manuela, and Artemio Baigorri. 2019. "Glocalising the theory of generations: The case of Spain.” Time \& Society 28(1): 333-357. doi: 10.1177/0961463X18783374.

Cohen, Phil, and Pat Ainley. 2000. "In the country of the blind?: Youth studies and cultural studies in Britain." Journal of Youth Studies 3(1): 79-95.

Díez-Nicolás, M. 2008. "Values and generations in Spain." In Changing Values, Persisting Cultures. Case Studies in Value Change, edited by Thorleif Petterson and Yilmas Esmer. Leiden, The Netherlands: Brill.

Edmunds, June, and Bryan S. Turner. 2002. Generational Consciousness, Narrative, and Politics: Rowman \& Littlefield Publishers.

Edmunds, June, and Bryan S. Turner. 2005 "Global generations: Social change in the twentieth century." The British Journal of Sociology 56(4): 559-577.

Eyerman, R, and B. S. Turner. 1998. "Outline of a theory of generations." European Journal of Social Theory 1: 91-106.

France, Alan, and Steven Roberts. 2015. "The problem of social generations: A critique of the new emerging orthodoxy in youth studies." Journal of Youth Studies 18(2): 215230. doi: 10.1080/13676261.2014.944122.

Greenberg, Eric, and Karl Weber. 2008. Generation We: How Millennial Youth are Taking Over America and Changing Our World Forever: Pachatusan.

Karisto, Antti. 2007. "Finnish baby boomers and the emergence of the third age." International Journal of Ageing and Later Life 2(2): 91-108.

Lindgren, Mats, Thomas Fürth, and Bernhard Lüthi. 2005. The MeWe Generation: Kairos Futures.

Madsen, Ole Jacob. 2018. Generasjon Prestasjon: hva er det som feiler oss? Oslo: Universitetsforlaget.

Mannheim, Karl. 1952 (1928). "The problem of generations.” In Karl Mannheim: Essays, edited by Paul Kecskemeti, 276-322. Routledge.

Pérez-Lanzac, Carmen. 2020. "La generación arrollada por dos crisis.” El País, April 26. https://elpais.com/sociedad/2020-04-25/la-generacion-arrollada-por-dos-crisis.html.

Pilcher, Jane. 1994. "Mannheim's sociology of generations: an undervalued legacy." British Journal of Sociology 45(3) (Sep.): 481-495. 


\section{Ida Tolgensbakk}

Prince, Alicia. Undated. 30 Things Only Those Who Are True '90s Kids Would Understand. Lifehack. https://www.lifehack.org/articles/communication/30-things-only-those-who -are-true-90s-kids-would-understand.html.

Purhonen, Semi. 2016. "Generations on paper: Bourdieu and the critique of 'generationalism'." Social Science Information 55(1): 94-114.

Shah, Yagana. 2014. 10 Indisputable Signs You're a Boomer. Huffington Post. https://ww w.huffpost.com/entry/signs-youre-a-baby-boomer_n_5883304.

Stopera, Matt. 2019.31 Things Boomers Love That Most Millennials Just Don't. Buzzfeed. https://www.buzzfeed.com/mjs538/things-boomers-absolutely-love-that-most-millenn ials.

Strauss, William, and Neill Howe. 1991. Generations: The History of America's Future, 1584 to 2069. New York: William Morrow and Company Inc.

Tolgensbakk, Ida. 2017a. "Pålogga lokalsamfunn.” Heimen 54(04): 319-328.

Tolgensbakk, Ida. 2017b. "Visual humor in online ethnicity: The case of swedes in Norway." In Race and Ethnicity in Digital Culture Our Changing Traditions, Impressions, and Expressions in a Mediated World, edited by Anthony Bak Buccitelli, 115-132. Santa Barbara: Praeger Books.

Twenge, J. M. 2006. Generation Me: Why Today's Young Americans Are More Confident, Assertive, Entitled - and More Miserable Than Ever Before. New York: Atria.

White, Jonathan. 2013. "Thinking generations." The British Journal of Sociology 64(2): 216-247.

Woodman, Dan. 2016. "The sociology of generations and youth studies." In Routledge Handbook of Youth and Young Adulthood. Routledge.

Wyn, J., and D. Woodman. 2006. "Generation, youth and social change in Australia." Journal of Youth Studies 9(5): 495-514. 